\title{
MicroRNA-mRNA regulatory networking fine-tunes the porcine muscle fiber type, muscular mitochondrial respiratory and metabolic enzyme activities
}

Xuan Liu, Nares Trakooljul, Frieder Hadlich, Eduard Muráni, Klaus Wimmers and Siriluck Ponsuksili*

\begin{abstract}
Background: MicroRNAs (miRNAs) are small non-coding RNAs that play critical roles in diverse biological processes via regulation of gene expression including in skeletal muscles. In the current study, miRNA expression profile was investigated in longissimus muscle biopsies of malignant hyperthermia syndrome-negative Duroc and Pietrain pigs with distinct muscle metabolic properties in order to explore the regulatory role of miRNAs related to mitochondrial respiratory activity and metabolic enzyme activity in skeletal muscle.

Results: A comparative analysis of the miRNA expression profile between Duroc and Pietrain pigs was performed, followed by integration with mRNA profiles based on their pairwise correlation and computational target prediction. The identified target genes were enriched in protein ubiquitination pathway, stem cell pluripotency and geranylgeranyl diphosphate biosynthesis, as well as skeletal and muscular system development. Next, we analyzed the correlation between individual miRNAs and phenotypical traits including muscle fiber type, mitochondrial respiratory activity, metabolic enzyme activity and adenosine phosphate concentrations, and constructed the regulatory miRNA-mRNA networks associated with energy metabolism. It is noteworthy that miR-25 targeting BMPR2 and IRS1, miR-363 targeting USP24, miR-28 targeting HECW2 and miR-210 targeting ATP5I, ME3, MTCH1 and CPT2 were highly associated with slow-twitch oxidative fibers, fast-twitch oxidative fibers, ADP and ATP concentration suggesting an essential role of the miRNA-mRNA regulatory networking in modulating the mitochondrial energy expenditure in the porcine muscle. In the identified miRNA-mRNA network, a tight relationship between mitochondrial and ubiquitin proteasome system at the level of gene expression was observed. It revealed a link between these two systems contributing to energy metabolism of skeletal muscle under physiological conditions.
\end{abstract}

Conclusions: We assembled miRNA-mRNA regulatory networks based on divergent muscle properties between different pig breeds and further with the correlation analysis of expressed genes and phenotypic measurements. These complex networks relate to muscle fiber type, metabolic enzyme activity and ATP production and may contribute to divergent muscle phenotypes by fine-tuning the expression of genes. Altogether, the results provide an insight into a regulatory role of miRNAs in muscular energy metabolisms and may have an implication on meat quality and production.

Keywords: Muscle, Mitochondrial respiratory activity, miRNA-mRNA network

\footnotetext{
* Correspondence: s.wimmers@fbn-dummertorf.de

Leibniz Institute for Farm Animal Biology (FBN), Institute for Genome Biology,

Wilhelm-Stahl-Allee 2, 18196 Dummerstorf, Germany
} 


\section{Background}

MicroRNAs (miRNAs) are endogenous small non-coding RNAs $\sim 22$ nt in length that play critical roles in diverse biological processes via epigenetic regulation of gene expression. Precursor miRNAs (pre-miRNA) are initially generated in nucleus and processed into an approximately $70 \mathrm{nt}$ long stem-loop structure. It is then exported to cytoplasm and processed by Dicer to generate miRNA/miRNA duplexes. One strand of which is incorporated with Agonaute to form RNA-Induced Silencing Complex (RISC) that targets mRNAs via base-pair complementary, typically to their 3' untranslated regions (3'UTR) or CDs and downregulates gene expression by either degradation of mRNA or repression of translation, while the other strand is usually discarded [1].

Skeletal muscle is highly metabolically active and valuable for meat-producing animals. Slow-twitch-oxidative (STO), fast-twitch-oxidative (FTO), and fast-twitchglycolytic (FTG) fiber were the three major muscle fiber types in pigs. Muscle fibers have strong association with muscle metabolic activities and meat quality such as tenderness, juiciness and color. Muscle containing a high proportion of oxidative fibers is often associated with higher fat content, oxidative enzyme activities and mitochondrial density [2-4]; a high ratio of FTG fibers is associated with high glycolytic enzyme activities. Previous research has identified several miRNAs are associated with meat quality such as miR-133, miR-221 and miR103 etc. in porcine skeletal muscle [5]. The polymorphisms in the porcine miR-133 and miR-208 are proposed as a genetic factor affecting muscle fibers and meat quality traits $[6,7]$. Since the critical roles of miRNAs such as myogenesis, adipogenesis and muscle development have been discovered in pig skeletal muscle [8-11], the understanding of the miRNA regulation in metabolic properties of skeletal muscle fibers could be key to improvement of meat quality [12]. MiR-210 and miR-338 could regulate the gene expression of oxidative phosphorylation (OXPHOS) machinery including complex IV subunits COX10, COXIV and ATP synthase subunits ATP5G1 [13, 14]. MiR-15a and miR-15b modulate the cellular ATP levels $[15,16]$. MiR-696 regulates the fatty acid oxidation and mitochondrial biogenesis through targeting peroxisome proliferator-activated receptor-gamma coactivator-1alpha (PGC-1 $\alpha)$ [17]. With those miRNAs identified, the lack of a comprehensive and systematic miRNA profiling associated with energy metabolism of skeletal muscle remains unraveled.

Our previous research on muscle transcriptional profile has revealed numerous biological pathways significantly associated with muscle fiber type, mitochondrial respiratory activity and metabolic enzymes [18]. It is of interesting to further investigate how miRNAs are involved in energy metabolism by fine-turning gene expression. In the present study, the miRNA transcriptome profiling of longissimus muscle (LM) samples obtained $24 \mathrm{~h}$ before slaughter of two pig breeds Duroc and Pietrain exhibiting divergent meat quality and muscle phenotypes provided a comprehensive insight into the discovery of miRNAs associated with muscle fiber, mitochondrial respiratory activity and metabolic enzyme activity. Muscle of Duroc pigs contains higher percentage of STO fibers, mitochondrial respiratory activity and higher fat content to improve the tenderness and juiciness of the meat. In comparison, PiNN pigs are more muscular and favorable for meat industry. Their skeletal muscles are leaner and contain more FTG fibers [18-20]. Hence Duroc and Pietrain pigs are great models to study energy metabolism of skeletal muscle. The miRNA and mRNA expression profile was then integrated based on their pairwise correlations and computational target prediction to construct the regulatory miRNA-mRNA networks which could potentially affect metabolic properties of skeletal muscle and hence meat quality. The illumination of miRNA-based regulatory metabolism could enrich our knowledge of the roles of miRNAs in achieving phenotypic diversity of skeletal muscle in different breeds.

\section{Methods}

\section{Animals and sample collection}

The experiment and muscle biopsy collection were approved and authorized by the German and European animal welfare regulations for animal husbandry, transport, and slaughter [19-21]. All experimental procedures, including animal care and tissue sample collection, followed guidelines for safeguarding and good scientific practice in accordance with the German Law of Animal Protection, officially authorized by the Animal Care Committee and authorities [Niedersächsischen Landesamt für Verbraucherschutz und Lebensmittelsicherheit (LAVES) 33.42502/01-47.05].

As previously described [19-21], Duroc and Pietrain (PiNN) pigs were raised until 180 days of age. To rule out the effects of the maglinant hyperthermia syndrome (MHS) locus, only muscle samples from MHS-negative genotype pigs were investigated. Muscle biopsies were collected from five female and male pigs of each breed $(n=20)$ for phenotypic measurements (see Additional file 1 for detailed phenotype definition and measurement) [18-21]. Biopsies were collected $24 \mathrm{~h}$ before slaughter from the longissimus muscle between 13th and 14th thoracic vertebrae. Muscle samples were frozen in liquid nitrogen and stored at $-80{ }^{\circ} \mathrm{C}$ until analysis.

\section{RNA isolation}

Small RNAs were isolated and enriched from longissimus muscle biopsies using a miReasy Mini kit and an 
RNeasy MinElute Cleanup kit (Qiagen) according to manufacturer's protocols. The quality and quantity of small RNA were assessed with an Agilent 2100 Bioanalyzer (Agilent) using an Agilent small RNA kit.

\section{MicroRNA microarray analysis}

The Affymetrix GeneChip miRNA 3.0 Array (Affymetrix) was used to determine the miRNA expression profile of the LM $24 \mathrm{~h}$ ante mortem of Duroc and PiNN pigs. It is comprised of 16,772 entries representing hairpin precursor, total probe set 19,724 for detection of most miRNA from 153 species (miRBase V.17). $200 \mathrm{ng}$ of small RNA were used in sample preparation using a FlashTag Biotin HSR RNA Labeling kit (Genisphere) for Affymetrix GeneChip miRNA Arrays. Each of the labeled RNA $(n=20)$ was then hybridized for $16 \mathrm{~h}$ to an Affymetrix GeneChip miRNA array according to manufacturer's recommendation (Affymetrix), washed and stained in the Affymetrix Fluidics Station 450, and scanned on the Affymetrix G3000 Gene Array Scanner. Expression Console software was used for robust multichip average (RMA) normalization and the detection of present miRNAs by applying the DABG (detection above background) algorithm. Further filtering was done by excluding probes that were present in less than $70 \%$ of the samples within each breed and annotated miRNAs that had sequence greater than or equal to $30 \mathrm{nt}$ in length. Three thousand five hundred eighty seven probes passed the quality filtering and were used for further analysis. The availability of expression data are in the Gene Expression Omnibus public repository with the GEO accession number GSE80198: GSM2120718-GSM2120737.

\section{Statistics and bioinformatics analyses}

Differential expression analysis for miRNA was performed using the ANOVA procedure in JMP genomics 7(SAS Institute). Breed was treated as a fixed effect. False discovery rate (FDR) was used to control an error rate of a multiple-hypothesis testing according to Benjamin \& Hochberg [22]. We used our previous microarray-based mRNA expression data to integrate with the differentially expressed miRNAs and scan for potential target genes. Pearson correlation of miRNA and mRNA expression levels was calculated.

Both RNAhybrid 2.1.2 and TargetScan 7.0 were used to predict targets of miRNAs. RNAhybrid (http:// bibiserv.techfak.uni-bielefeld.de/rnahybrid) is computational software that detects the most energetically favorable hybridization sites of a small RNA within a large RNA [23, 24]. The miRNA probe sets were tested with the following parameters: number of hits per target $=1$ and energy cutoff $=-25 \mathrm{kcal} / \mathrm{mol}$ and maximal internal or bulge loop size per side $=4$. TargetScan (http:// targetscan.org/) was used to predict the target gene candidates based on complementarity of the miRNA seed sequence (position 2-8 of the miRNA $5^{\prime}$-end) and target binding site on the $5^{\prime}$ UTR, $3^{\prime}$ UTR and protein coding region of the porcine mRNA sequences (Sus scrofa 10.2 download from NCBI: http://www.ncbi.nlm.nih.gov/ on 1.9.2015) [25]. Hafner et al. and Chi et al. have found that Argonaute-bound target sites in coding sequences (CDs) are as numerous as those located in 3' UTR in both HEK293 cells (50 \% CDs vs 46 \% 3'UTR) [26] and mouse brain (25\% CDs vs $32 \% 3^{\prime}$ UTR) [27]. Other research suggests that miRNA target sites in 3' UTR are more efficient at triggering mRNAs degradation while CDs and 5'UTR located sites can effectively repress translation $[28,29]$. Xu et al. develop novel computational approach for target prediction with sites located along the entire gene sequences to increase the percentage of true positive targets [30]. Hence 5' UTR, CDs and 3'UTR were included in this study to improve the sensitivity of miRNA target identification and avoid a substantial number of missing targets. Transcripts that negatively correlated with miRNA and predicted as potential targets were further passed to functional analysis.

IPA software (Ingenuity System, https://www.ingenuity.com) was used for functional analysis of potential miRNA target genes. It categorizes genes based on annotated gene functions and statistically tests for overrepresentation of functional terms within the gene list using Fisher's Exact Test. The miRNA-mRNA regulatory networks were visualized using Cytoscape V3.2.1 (http:// cytoscape.org) [31].

\section{Quantitative real time PCR (qPCR) for microRNA microarray (miChip) validation}

Four miRNAs (ssc-miR-24-3p, ssc-miR-30a-5p, ssc-miR126 and ssc-miR-145) related to energy metabolism were validated by qPCR of each individual sample $(n=20)$. The same samples were used for both qPCR validation and miRNA-chips. The cDNA was synthesized from $250 \mathrm{ng}$ isolated miRNAs using an $\operatorname{NCode}^{\mathrm{TM}} \mathrm{VILO}^{\mathrm{TM}}$ miRNA cDNA Synthesis Kit (Invitrogen) according to manufacturer's protocols. Real-time PCR was performed using the EXPRESS SYBR GreenER ${ }^{\mathrm{TM}}$ miRNA qRT-PCR Kit with premixed ROX (Invitrogen) according to manufacturer's protocols. All measurements were performed in duplicates. The thermal parameters were $50{ }^{\circ} \mathrm{C}$ for 2 min, $95{ }^{\circ} \mathrm{C}$ for $2 \mathrm{~min}$, followed by 45 cycles of $95{ }^{\circ} \mathrm{C}$ for $15 \mathrm{~s}$ and $60{ }^{\circ} \mathrm{C}$ for $1 \mathrm{~min}$. The universal qPCR primer was provided in the kit and the miRNA-specific forward primers were designed for the miRNAs of interest. The designed primer sequence information is accessible in Additional file 2. Geometric mean of the $5 \mathrm{~S}$ and U6 transcription levels was used as an internal standard to normalize the miRNA expression value. Correlation 
coefficient analysis between the miChip and qPCR data was calculated using SAS 9.3 (SAS Institute).

\section{Results \\ Differentially expressed miRNAs between Duroc and Pietrain}

Out of 3587 probes quality-filtered probes, 58 probes belonged to 27 unique mature miRNA sequences were differentially expressed $(p<0.05$, FDR $<0.2)$ between Duroc and PiNN using ANOVA on JMP Genomics 7. Among these, 33 probes belonged to 8 mature miRNA sequences were up-regulated in Duroc pigs, while 25 probes belonged to 19 different mature miRNA sequences were up-regulated in PiNN pigs (Additional file 3). Among these, miR-363, miR-423 and miR-34 were the top three upregulated miRNAs in Duroc pigs with fold change ranging from 3.29 to 1.68. Whereas the top three upregulated miRNAs in PiNN were miR-4687, miR-3619 and miR-22 with fold change ranging from 3.45 to 2.71 .

\section{Correlation between differentially expressed miRNAs and target mRNAs}

The mRNA expression data of matched samples from our previous study (GEO accession number GSE69840: GSM1709900 - GSM1709919) were used for a pairwise correlation analysis [18]. In total, 2345 mRNA probes were differentially expressed $(p<0.05$, FDR $<0.05)$ between two breeds. A pairwise correlation coefficient analysis was computed between 58 miRNA probes and 2345 mRNA probes. Among the 136,010 Pearson correlation coefficients, 12,408 negative correlated miRNA-mRNA pairs were detected at $p<0.05$ and FDR $<0.05$ for correlation between miRNA and mRNA. Computational target prediction was performed using Targetscan and RNA hybrid. After combining the correlation analysis and target prediction results, 598 miRNA-mRNA pairs containing 340 genes and 11 mature miRNA sequences were retained (Additional file 4). The heat map and hierarchical clustering of miRNA-mRNA pairs based on their expression levels (lsmeans) shown in Fig. 1 demonstrates an inverse relationship between mRNAs and mRNA target candidates. All the target genes were further analyzed with IPA to identify prominent functions and pathways that may contribute to divergent muscle metabolic properties between the two breed types. Target genes assigned to the functional categories related to skeletal and muscular system development and function as well as carbohydrate metabolism were focused on. The top three canonical pathways for Duroc up-regulated target genes were protein ubiquitination pathway, p70S6K signaling and mouse embryonic stem cell pluripotency, while geranylgeranyl diphosphate biosynthesis, phagosome maturation and urate biosynthesis/Inosine $5^{\prime}$-phosphate degradation for PiNN up-regulated target genes. A representative miRNA-mRNA regulatory network of focused biological pathways depicted in Fig. 2 illustrates a complex relationship and networking of the two biomolecule types.

\section{Correlation between miRNA expression and phenotypic traits}

The expression of 3587 miRNA probes was calculated for the correlation with traits of muscle fiber composition, mitochondrial respiratory activity and metabolic enzyme activity in both Duroc and PiNN pigs. In total, 3263 miRNA-phenotype pairs containing 1864 miRNA probes belonged to 757 mature miRNA sequences were identified at $p<0.05$ shown correlation between miRNA and at least one of the 19 phenotypes. The top 100 significant miRNAs correlated to phenotypes were shown in Additional file $5(p<\sim 0.001)$. Table 1 showed the top five miRNAs significantly correlated to each phenotype.

\section{Integration of correlated miRNAs, mRNAs and phenotypic traits}

Correlations between gene expression derived from post quality-filtered 17,820 mRNA probes and each phenotypic- trait were calculated for both Duroc and PiNN pigs. In total, 24,374 mRNA-phenotype pairs containing 11,091 mRNA probes belonging to 7489 genes were identified at $p<0.05$. The top 100 significant mRNAs correlated with phenotypes are accessible in Additional file $6 \quad(p<0.0002)$. Pairwise correlation coefficient analysis was then performed between the identified 1864 miRNA probes and 11,091 mRNA probes which correlated with at least one of the 19 phenotypes. After combining with the target prediction results, 26,861 miRNA-mRNA pairs containing 3182 genes and 387 miRNAs $(p<0.05)$ were identified to correlate with at least one phenotype. The top ten miRNA-mRNA pairs for each phenotype were shown in Fig. 3 and Additional file 7 $(p<0.05$, FDR $<0.24)$.

\section{Correlation relationship between mitochondrial and UPS related genes}

From all identified top 10 miRNA-mRNA pairs associated with each phenotypic trait (Fig. 3), the expression correlation between 9 selected nuclear-encoded mitochondrial-related genes and 7 selected UPS-related genes were calculated. In Table 2, mitochondria related genes: ATP synthase, mitochondrial F0 complex, subunit E (ATP5I), Malic enzymes 3 (ME3), mitochondrial carrier 1 (MTCH1), cytochrome P450, family 24, subfamily A, peptide 1 (CYP24A1), kinesin family member 1 

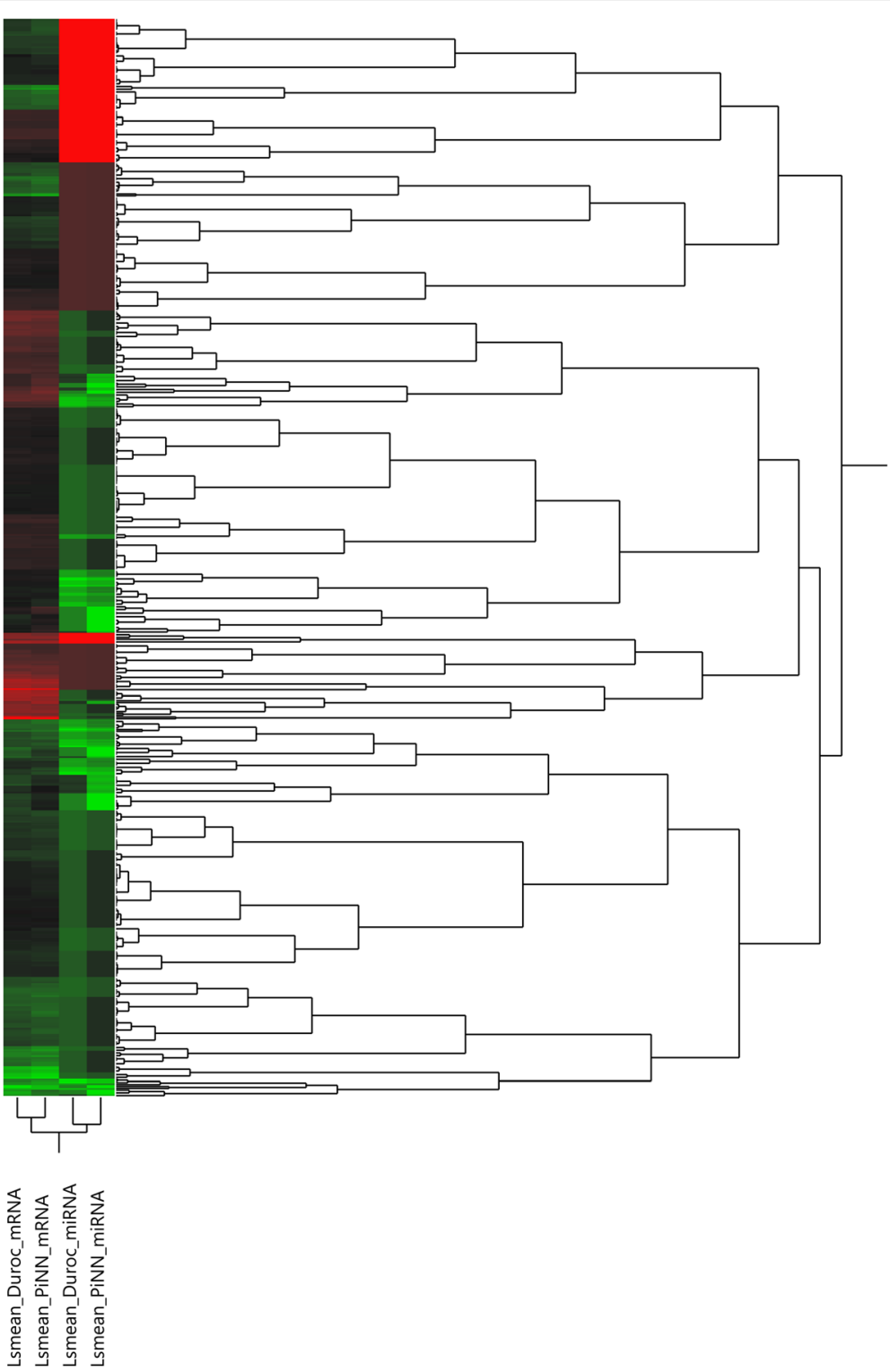

Fig. 1 Heatmaps and hierarchical cluster of mRNA and miRNA pairs based on Least squares (Ls) means of differentially expressed mRNA and miRNA (FDR $<0.05$ ) between breed Duroc and PiNN

binding protein (KIAA1279), prohibitin 2 (PHB2), pyruvate dehydrogenase alpha 1 (PDHA1) and ubiquinolcytochrome c reductase complex chaperone $(U Q C C)$ were significantly correlated with at least one of the six UPSrelated genes: Sus scrofa similar to E3 ubiquitin-protein ligase HECW2 (HECW2), ubiquitin specific peptidase 24 (USP24), ubiquitin family domain containing 1 (UBFD1), mitochondrial ubiquitin ligase activator of NFKB 1-like (MUL1), amyloid beta (A4) precursor protein $(A P P)$ and heat shock $70 \mathrm{kDa}$ protein 2 (HSPA2) at $p<0.05$.

\section{qRT-PCR validation}

The expression of ssc-miR-24-3p, ssc-miR-30a-5p, sscmiR-126 and ssc-miR-145 were random selected for validation by qRT-PCR. The correlation coefficient between qPCR and miChip data ranged from 0.543 $(p=0.0134)$ to $0.6833(p=0.0009)$, suggesting a good concordance between miChip and qPCR results, as shown in Fig. 4.

\section{Discussion}

Duroc and Pietrain are divergent for different muscle characteristics and meat quality. Duroc pigs are fattier and their skeletal muscle contains larger amount STO fibers which are generally associated with higher oxidative enzyme activities, mitochondrial respiratory activity and the storage of lipid to improve the tenderness and juiciness of the meat, whereas Pietrain pigs are more 


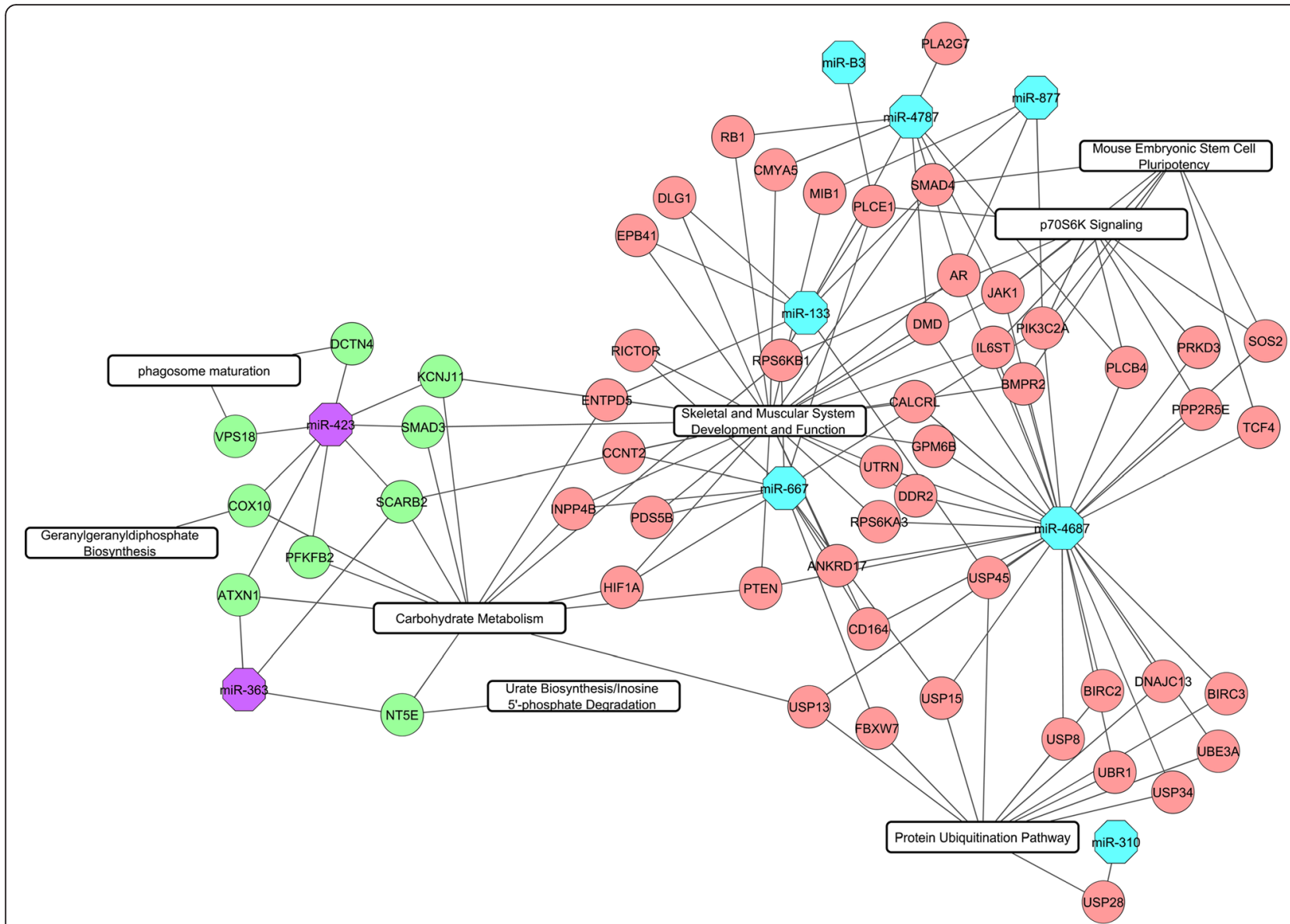

Fig. 2 Differentially expressed miRNA-mRNA pairs and regulatory network between breed Duroc and PiNN. Blue indicates miRNAs with higher expression in PiNN, purple indicates miRNAs with higher expression in Duroc, red indicates genes with higher expression in Duroc and green indicates genes with higher expression in PiNN

muscular and their muscles are more lean and contain higher percentage of FTG fibers which are associated with higher glycolytic enzyme activities [2, 18-20, 32, 33]. The higher percentage of FTG fibers may result in lower capillarization, insufficient delivery of oxygen and glycogen depletion, which ultimately lead to dry, firm, and dark meat [34,35]. Since microRNAs have been known as critical regulators in energy metabolism of skeletal muscle, in the present study, miRNA expression profiling and functional analysis may shed light on miRNA-based epigenetic regulatory mechanism of muscle fiber type and metabolic enzyme activity and hence may be translated to improvement of meat quality.

The miRNA profile of porcine skeletal muscle has been investigated in several studies and the miRNAmRNA networks are constructed [36-38]. Hou et al. analyzes the miRNA and mRNA profile for Landrace (lean-type) and Tongcheng (obese-type) pigs [36]. In both the study of Hou et al. and our present study, biological process of muscle development was shown in the identified differentially expressed miRNA-mRNA network and it highlights the importance of the regulatory role of miRNAs in diverging porcine muscle development between obese-type and lean-type pigs. Further, some miRNAs such as miR-363, miR-133 and miR-423 were identified in the network of both studies. Tang et al. investigated the miRNA and mRNA expressions of skeletal muscle for Landrace and Tongcheng pigs at 33, 65 and 90 days to explore prenatal muscle development while Jing et al. construct differentially expressed miRNA-mRNA network between different residual feed intake in pigs $[37,38]$.

\section{Roles of the differentially expressed miRNAs and their target genes in divergent muscle characteristics}

To understand the regulatory role of miRNAs that may contribute to phenotypic variation of the skeletal muscle in different pig breeds, differentially expressed miRNAs and mRNAs between the two breeds were integrated, so that the key target genes regulated by key miRNAs were identified. Functional analysis results showed that the 
target genes were significantly enriched for various muscle related bio-functions suggesting biological related results rather than random noise. The top canonical pathway for Duroc-up regulated genes was protein ubiquitination pathway containing genes of USP28, USP8, USP45, USP15, USP13, UBR1, DNAJC13, FBXW7, BIRC3, USP34, UBE3A, BIRC2. The ATP-dependent ubiquitin is mediated by ubiquitin-activating enzyme E1, specific ubiquitin-conjugating-enzyme E2 and ubiquitin protein E3 to promote protein degradation via the $26 \mathrm{~s}$ proteasome and has implications on meat quality and muscle atrophy [39-42]. In our study, USP45 and USP28 were predicted as a direct target of miR-133 and miR-310 respectively. MiR-133b could influence both major apoptosis pathways and wound healing [43, 44], and most importantly, the polymorphisms in the porcine MiR206/MiR133b cluster are proposed as a genetic factor affecting muscle fibers and meat quality traits [6]. MiR-311-3p belongs to miR-310 miRNA family and its loss of function can cause defects in energy metabolism and deregulation of nutritional homeostasis-associated genes [45]. MiR-363 has been discovered as a negative regulator of adipogenesis in adipose tissue-derived stromal cells by directly targeting the 3'UTR of E2F3 [46]. This is in line with our study that the expression level of miR-363 is higher in Duroc than PiNN with average fold change more than 3 . Other Duroc up-regulated genes such as CMYA5, AR, RB1 and BMPR2 in functional category of skeletal and muscular system development and function were regulated by miR-4787, miR-877 and miR-4687 etc. Cardiomyopathy associated 5 (CMYA5) also called TRIM76 belongs to the tripartite motif super family of proteins (TRIM). Its interaction with both Mband Titin and Calpain 3 suggests its relevance to Limbgirdle Muscular Dystrophies [47]. One SNP (A7189C) of CMYA5 is significantly associated with water loss and intramuscular fat, which proposes the porcine CMYA5 as a potential candidate gene for meat quality [48]. Androgen Receptor (AR) is a steroid-hormone activated transcriptional factor. The androgen-AR signaling pathway promotes the slow-twitch muscle fiber formation in skeletal muscle by increasing the expression of slowtwitch-specific genes and suppressing the fast-twitchspecific genes [49].. Moreover, retinoblastoma 1 (RB1) has been identified to be related to Marbling trait in cattle via gene co-expression analysis [50]. Bone Morphogenetic Protein Receptor type II (BMPR2) encodes a member of the bone morphogenetic protein receptor family of transmembrane serine/threonine kinases. It is essential for BMP signaling and may be involved in the regulation of adipogenesis and hence in Obesity [51]. All the above Duroc-up regulated genes with their corresponding down regulated miRNAs could contribute to the higher amount of oxidative muscle fibers and fat content. On the other hand, PiNN-up regulated genes SMAD3 and PFKFB2 were regulated by miR-423. These

Table 1 The top five significant miRNAs correlated to phenotypes in both Duroc and PiNN pigs

\begin{tabular}{|c|c|c|c|}
\hline Phenotype & Top five significant miRNAs & $P$-value & |Correlation| \\
\hline STO & miR-130, miR-208, miR-363, miR-24, miR-126 & $3.123 \mathrm{E}-04-1.195 \mathrm{E}-03$ & $0.803-0.753$ \\
\hline FTO & miR-22, miR-166, miR-1892, miR-1343, miR-143 & $1.222 \mathrm{E}-03-4.514 \mathrm{E}-03$ & $0.752-0.689$ \\
\hline FTG & miR-99, miR-499, let-7, miR-181, miR-154 & 1.577E-04-3.337E-04 & $0.824-0.801$ \\
\hline State3_pyruvate & miR-30, miR-196, miR-190, miR-363, miR-95 & 1.508E-03-7.169E-03 & $0.661-0.581$ \\
\hline State3_succinate & miR-126, miR-196, miR-363, miR-1892, miR-30 & 7.329E-04-4.205E-03 & $0.691-0.611$ \\
\hline State4_CAT & miR-196, miR-2012, miR-192, miR-202, miR-17 & $2.484 \mathrm{E}-04-1.360 \mathrm{E}-02$ & $0.731-0.542$ \\
\hline RCl_pyruvate & miR-17, miR-182, miR-203, miR-27, miR-378 & $6.558 \mathrm{E}-03-1.258 \mathrm{E}-02$ & $0.587-0.547$ \\
\hline RCl_succinate & miR-182, miR-203, miR-17, miR-27, miR-542 & 3.630E-04-4.034E-03 & $0.718-0.613$ \\
\hline GP & miR-148, let-7, miR-194, miR-7, miR-25 & 3.063E-03-1.477E-02 & $0.627-0.536$ \\
\hline PFK & miR-130, miR-208, miR-193, miR-32, miR-24 & 5.944E-04-1.455E-03 & $0.700-0.663$ \\
\hline $\mathrm{LDH}$ & miR-17, miR-58, miR-15, miR-769, miR-345 & $1.090 \mathrm{E}-04-4.384 \mathrm{E}-03$ & $0.758-0.609$ \\
\hline CS & miR-338, miR-30, miR-17, miR-182, miR-455 & 3.970E-05-1.959E-03 & $0.786-0.649$ \\
\hline Complexl & miR-182, miR-181, miR-143, miR-28, miR-765 & $2.691 \mathrm{E}-04-1.620 \mathrm{E}-03$ & $0.743-0.672$ \\
\hline Complexll & miR-182, miR-1, miR-1307, miR-203, miR-499 & 2.557E-03-2.458E-02 & $0.666-0.527$ \\
\hline ComplexIV & miR-196, let-7, miR-451, miR-128, miR-99 & 3.668E-03-7.785E-03 & $0.618-0.577$ \\
\hline IMP & miR-168, miR-166, miR-58, miR-223, let-7 & $3.908 \mathrm{E}-04-1.382 \mathrm{E}-02$ & $0.745-0.569$ \\
\hline AMP & miR-10, miR-126, let-7, miR-27, miR-450 & $9.860 \mathrm{E}-05-5.804 \mathrm{E}-04$ & $0.789-0.730$ \\
\hline ADP & miR-15, miR-885, miR-322, miR-450, miR-338 & $1.316 \mathrm{E}-04-4.540 \mathrm{E}-03$ & $0.781-0.636$ \\
\hline ATP & miR-15, miR-450, miR-210, miR-885, miR-451 & $4.811 \mathrm{E}-04-9.562 \mathrm{E}-03$ & $0.737-0.593$ \\
\hline
\end{tabular}




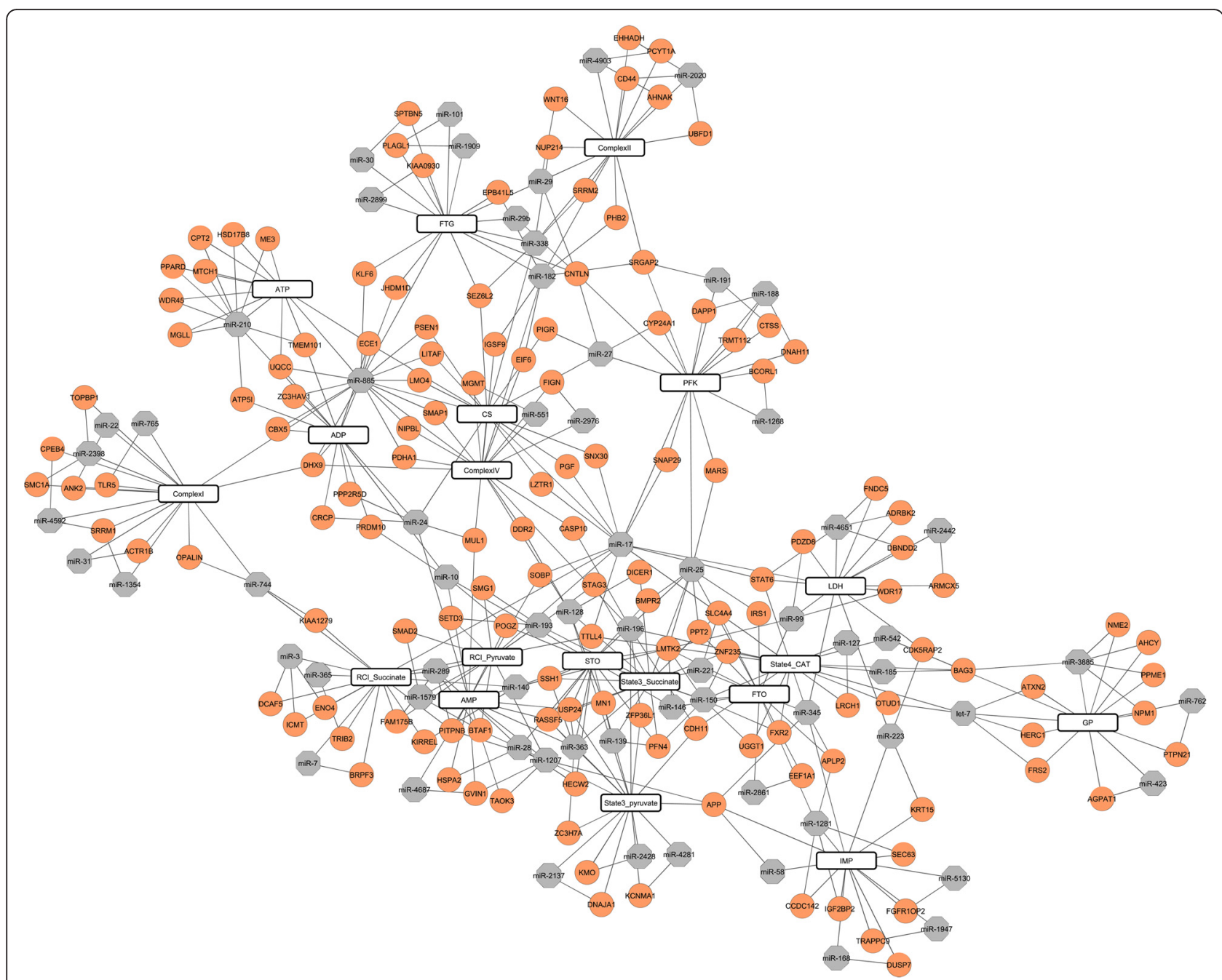

Fig. 3 Regulatory network of miRNA-mRNA associated with muscle fiber composition, mitochondrial respiratory activity, metabolic enzyme activity and adenine nucleotide concentration for breed Duroc and PiNN. Genes were colored with orange while miRNAs with grey

Table 2 Correlation between mitochondrial and UPS related gene expressions

\begin{tabular}{|c|c|c|c|c|c|c|c|c|c|c|}
\hline \multirow[t]{2}{*}{ Genes } & & & \multicolumn{8}{|c|}{ Mitochondria related genes } \\
\hline & & & ATP5I & ME3 & MTCH1 & CYP24A1 & KIAA1279 & PHB2 & PDHA1 & UQCC \\
\hline \multirow[t]{12}{*}{ UPS related genes } & HECW2 & $r$ & 0.386 & 0.623 & 0.494 & -0.318 & -0.392 & -0.306 & 0.586 & 0.509 \\
\hline & & $p$ & 0.093 & 0.003 & 0.027 & 0.171 & 0.087 & 0.189 & 0.007 & 0.022 \\
\hline & USP24 & $r$ & -0.285 & -0.284 & -0.376 & 0.160 & 0.542 & 0.478 & -0.422 & -0.281 \\
\hline & & $p$ & 0.224 & 0.226 & 0.102 & 0.501 & 0.014 & 0.033 & 0.064 & 0.231 \\
\hline & UBFD1 & $r$ & 0.512 & 0.501 & 0.746 & 0.069 & -0.512 & -0.669 & 0.477 & 0.515 \\
\hline & & $p$ & 0.021 & 0.024 & 0.0002 & 0.772 & 0.021 & 0.001 & 0.034 & 0.020 \\
\hline & MUL1 & $r$ & 0.336 & 0.083 & 0.131 & 0.657 & 0.460 & 0.224 & -0.375 & 0.051 \\
\hline & & $p$ & 0.147 & 0.726 & 0.583 & 0.002 & 0.041 & 0.341 & 0.103 & 0.832 \\
\hline & $A P P$ & $r$ & 0.214 & 0.486 & 0.463 & -0.368 & -0.300 & -0.292 & 0.214 & 0.327 \\
\hline & & $p$ & 0.365 & 0.030 & 0.040 & 0.110 & 0.199 & 0.211 & 0.364 & 0.159 \\
\hline & HSPA2 & $r$ & 0.414 & 0.484 & 0.566 & -0.212 & -0.502 & -0.474 & 0.537 & 0.274 \\
\hline & & $p$ & 0.070 & 0.031 & 0.009 & 0.369 & 0.024 & 0.035 & 0.015 & 0.242 \\
\hline
\end{tabular}


ssc-miR-24-3p

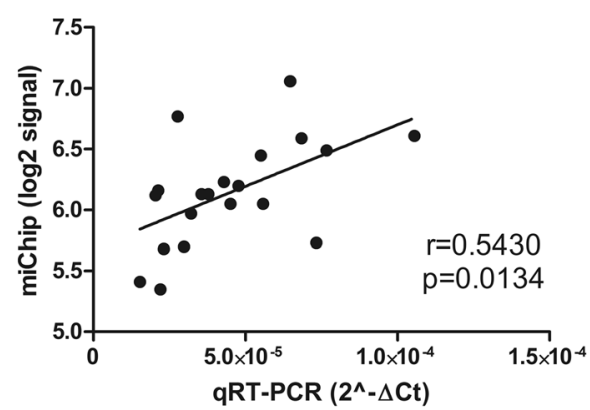

sSc-miR-126

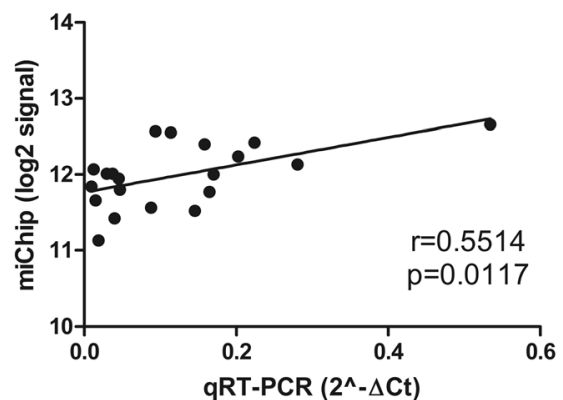

ssc-miR-30a-5p

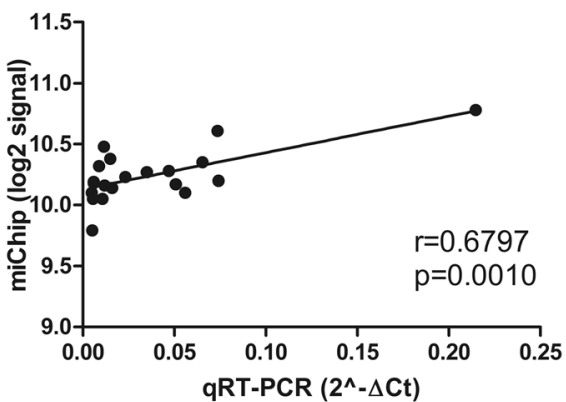

SSC-miR-145

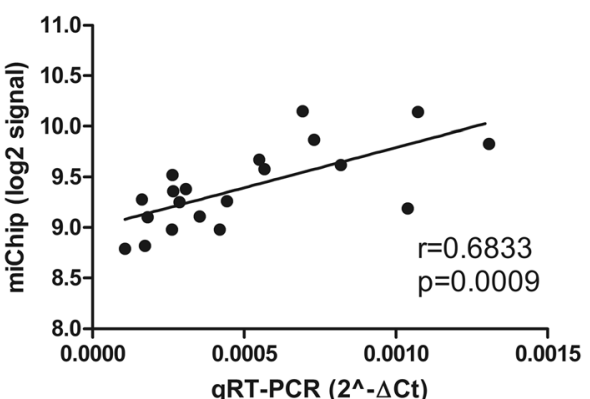

Fig. 4 qPCR validation of miChip results for four microRNAs: ssc-miR-24-3p, ssc-miR-30a-5p, ssc-miR-126 and ssc-miR-145. Plot between qPCR $(2 \wedge-\Delta C t$ on the $x$-axis) and miChip (log2 signals on the $y$-axis) for each miRNA. The corresponding correlation coefficient $(r)$ and $p$ values are shown

two genes are involved in not only muscle fiber specificity but also the promotion of glycolysis in skeletal muscle. SMAD family member 3 (SMAD3) promotes muscle atrophy in vivo by regulating atrogin-1, mTOR and protein synthesis [52]. It suppresses the expression of peroxisome proliferator-activated receptor $\gamma$ coactivator 1- $\alpha(P G C-1 \alpha)$ [53], which is a master coordinator to control mitochondrial biogenesis and drives the formation of slow-twitch muscle fibers [54, 55]. Fructose -2, 6biphosphatase 2 (PFKFB2) can promote glycolysis by controlling the level of Fructose 2, 6- bisphosphate, which is an allosteric activator of phosphofructokinase (PFK-1) [56]. Collectively, we demonstrate that differential miRNAs and target gene candidates assemble regulatory networks that may fine-tune the expression of genes within the pathways and shape the related phenotypes among pig breeds.

\section{Phenotype-correlated microRNAs link to various processes in energy metabolism}

Numerous studies have revealed the critical roles of miRNAs in skeletal muscle development and the irregular miRNA expression contributes to various muscular disorders [57]. Table 1 shows the top five miRNAs significantly correlated to each phenotypic trait including muscle fiber type, mitochondrial respiratory activity (MRA) and metabolic enzyme activities for Duroc and
PiNN pigs. Both positive and negative correlations were included to discover any potential links between miRNAs and phenotypes. STO, FTO, and FTG fibers were three major muscle fiber types in pigs which are strong associated with muscle metabolic activities and meat quality. MiRNAs such as miR-208, miR-499, miR-130 and miR-363 showed highly significant correlation with muscle fiber types. MiR-208 and miR-499 play a dominant role in the specification of muscle fiber identity by inducing the type I fiber program via targeting Sox6 which acts as a repressor of slow-twitch genes [58-60]. MiR-130b belongs to miR-130 family directly targets gene PGC- $1 \alpha$, which is a master regulator for mitochondrial biogenesis and its activation promotes the slow, oxidative myogenic program in mice and drives the formation of slow-twitch muscle fibers in cultured muscle cells $[54,61]$. In $\mathrm{C} 2 \mathrm{C} 12$ cells, miR-130b could modulate cellular ATP levels by targeting electron transport chain subunits Ndufb7 and Cox6a2 [16]. As previously mentioned, miR-363 has been discovered as a negative regulator of adipogenesis in adipose tissue-derived stromal cells by directly targeting the 3'UTR of E2F3 [46]. Since lipids are stored mainly in STO muscle fibers to improve tenderness and juiciness of the meat [33], and muscles containing more STO fibers are associated with higher oxidative enzyme activities and mitochondrial respiratory activity [2], it is expected that miR-363 shows high 
correlation with STO muscle fiber type and mitochondrial respiratory activity including state 3 pyruvate and state 3 succinate. MiR-30 family members haven been demonstrated to control calcium signaling by directly inhibiting a $\mathrm{Ca}^{2+}$ transporter TRPC6 etc. [62]. Considering the crucial regulatory role of calcium signaling in mitochondrial ATP production, it was not unexpected that miR-30 was associated with mitochondrial respiratory activity including state 3 pyruvate and state 3 succinate and TCA involved CS enzyme activity. Furthermore, miR-30 directly targets Prdm1 to promote fast muscle formation since Prdm 1 regulates muscle fiber differentiation by repressing the transcription factor Sox6 which acts as a repressor of slow-twitch-specific gene expression $[60,63]$. All these reinforced the association between STO fiber, mitochondrial respiratory activity and fat content. MiR-196 was highly correlated to mitochondrial state 3 and state 4 respiration rate and Complex IV activity. MiR-196a displays a tissue-specific expression pattern in porcine and plays a role in porcine adipose development via inducing the expression of adipocyte specific markers, lipid accumulation and triglyceride content [64]. MiR-542 was significantly correlated to RCI succinate. MiR-542-3p directly targets bone morphogenetic protein 7 (BMP7), which induces differentiation of adipose derived mesenchymal stem cells into brown adipocytes and increases mitochondrial activity in mature brown adipocytes [65-67]. MiR-1 was correlated to Complex II activity in the present study. MiR-1 family is abundantly expressed in cardiac and skeletal muscle. It post-transcriptionally represses the expression of genes in antioxidant network and thus influences susceptibility to cardiac oxidative stress of miR-1 transgenic mice [68]. Moreover, it was proposed as a candidate gene associated with muscle fiber type composition [69]. MiR-7, miR-194 and miR-25 were identified to correlate with GP activity. Both miR-7 and miR-194 could directly target and suppress the expression of insulin-like growth factor 1 receptor (IGF-1R) whereas miR-25 regulates insulin synthesis at its mRNA level [70-72]. Since insulin and insulin-like growth factor system are crucial for normal glucose homeostasis [73, 74], it is likely that miR-7 and miR-194 could play a role in glucose metabolism via IGF-1R and insulin. MiR-210, miR-15 and miR-338 were highly correlated to the concentration of ADP and ATP in muscle cells. MiR-210 and miR-338 regulate the expression of oxidative phosphorylation (OXPHOS) machinery including complex IV subunits COX10, COXIV and ATP synthase subunits ATP5G1 correspondingly $[13,14]$. The fully assemble of OXPHOS system could directly contribute to the ATP production. Furthermore, the modulation of cellular ATP levels by miR-15b was supported by other work as well [15]. Overall, our results and previous reports functionally link miRNAs to muscle fiber specificity, mitochondrial respiration, adipogenesis, glucose metabolism and ATP production and further suggest an essential role of miRNAs in energy metabolism.

\section{Phenotype-correlated miRNA-mRNA regulatory network link to energy metabolism}

Based on the identified miRNAs that highly correlated with the phenotypes, we further integrated the miRNA and mRNA expression profiles to identify miRNAs regulated genes that influence energy metabolism. The microRNA-mRNA regulatory network was constructed using the following criteria: 1) The expressions of both miRNAs and target mRNAs were correlated to the phenotypical traits 2) The gene expression level was negatively correlated with the expression of its miRNA regulator 3) The gene was computationally predicted as a target gene of the corresponding miRNA. It is noteworthy that miR-25 together with its target genes Bone Morphogenetic Protein Receptor type II (BMPR2) and insulin receptor substrate 1 (IRS1) were correlated to STO and FTO muscle fibers. MiR-25 has been documented to be abundant in cardiomyocytes. It targets the mitochondrial calcium uniporter (MCU) and $\mathrm{Ca}^{2+}$ transporting ATPase (ATP2A2) and plays a role in cardiac contractility $[75,76]$. In the present study, miR- 25 was proposed to target both genes BMPR2 and IRS1. BMPR2 encodes a member of the bone morphogenetic protein receptor family of transmembrane serine/threonine kinases. It is essential for BMP signaling and may be involved in the regulation of adipogenesis and hence in obesity [51]. IRS1 is a major molecule mediating insulinsignaling pathways. Insulin not only regulates stimulation of protein synthesis and glucose storage [77], but also has effect on mitochondrial function and oxidative capacity of skeletal muscle via increasing the expression level of complex I and complex IV and hence ATP production [78]. MiR-363 and its target gene ubiquitin specific peptidase 24 (USP24) were correlated to STO fibers, mitochondrial respiratory activity including state 3 pyruvate and state 3 succinate, and AMP concentration in muscle cells, while miR-28 and its target gene HECW2 were correlated to STO muscle fibers. USP24 belongs to a large family of cysteine proteases that function as deubiquitinating enzymes. HECW2 encodes HECT, C2 and WW domain containing E3 ubiquitin protein ligase 2 which is a major component of ubiquitin proteasome system (UPS). UPS utilizes ATP to promote protein degradation and regulate muscle mass. Accumulated ubiquitin proteins in fast- to slow- transforming rabbit muscle revealed a possible role of UPS in muscle fiber specificity [79]. Interestingly, miR-363 has been discovered as a negative regulator of adipogenesis as described previously [46]. Misregulation of miRNAs 
belonging to miR-23a/27a/24-2 cluster has been recently associated to hypertrophic cardiomyopathy and skeletal muscle atrophy [80]. MiR-27 was almost sixfold greater in slow-twitch than in fast-twitch muscle in vivo. It posttranscriptionally regulates fast-specific myostatin (MSTN) expression, which mature mRNA level is sixfold greater in fast vs slow muscle [81]. In this study, miR-27 was identified to be associated with PFK activity - a rate-limiting enzyme in glycolysis and potentially target cytochrome P450, family 24, subfamily A, polypeptide 1 (CYP24A1), which catalyzes the side-chain oxidation of vitamin $D$ [82]. The vitamin D pathway has the suppressive effect on brown adipocyte differentiation and mitochondrial respiration [83]. MiR-210 and its predicted targets ATP5I, ME3, MTCH1 and CPT2 were highly correlated to ADP and ATP concentration in present study. MiR-210 modulates mitochondrial function, decreases COX10 expression and activates the generation of reactive oxygen species (ROS) [14]. ATP5I encodes ATP synthase mitochondrial F0 complex subunit $E$ and it is required for the full assembly of the ATP synthase and ATP production [84]. ME3 encodes mitochondrial NADP (+)-dependent malic enzyme 3 . The regulation of human mitochondrial NADP (+)-dependent malic enzyme by ATP and fumarate may be crucial for the metabolism of glutamine for energy production [85]. MTCH1 and CPT2 encode for mitochondrial carrier 1 and carnitine palmitoyltransferase 2 respectively. MTCH1 also known as Presenilin 1-associated protein (PSAP) which acts as a proapoptotic mitochondrial protein induce apoptosis independent of the proapoptotic proteins Bax and Bak [86]. The two isoforms of MTCH1 share two proapoptotic domains and multiple internal signals for import into the mitochondrial outer membrane [87]. Fatty acid is a major energy source for the heat and skeletal muscle. CPT2 together with CPT1 are involved in beta-oxidation of long chain fatty acids in the mitochondria [88]. Altogether suggests that miR-210 and its target genes ATP5I, ME3, MTCH1 and CPT2 are likely to be involved in ATP production, apoptosis and betaoxidation of long fatty acids in mitochondria. We have demonstrated that correlation relationship between miRNA and target mRNA can be used to functionally link to phenotypes of interest such as muscle fiber type specification, mitochondrial respiration activity and metabolic enzymes related to ATP production.

\section{Crosstalk between mitochondria and UPS in skeletal muscle}

Up to now we have shown that the identified miRNAmRNA networks are linked to muscle fiber types, oxidative enzyme activities and ATP generation. Some of these target genes are involved in mitochondrial function and UPS. An interesting finding was the significant correlation between mitochondrial and UPS related gene expressions. More specifically, mitochondrial related genes including ATP5I, ME3, MTCH1, CYP24A KIAA1279, $P H B 2, P D H A 1$ and $U Q C C$ were highly correlated to at least one of the UPS-related genes including $H E C W 2$, USP24, UBFD1, MUL1, APP and HSPA2.

The tightly interdependent relationship between mitochondria and UPS system has been described in many age-related diseases such as Alzheimer's and Parkinson's disease [89-91]. Our present study revealed a link between these two systems at the level of gene expression under normal state, since all the investigated animals were healthy. In other words, both mitochondria and UPS might contribute to energy metabolism of skeletal muscle via fine-turning the gene expression by miRNAs under physiological conditions.

The HECT, C2 and WW domain containing E3 ubiquitin protein ligase 2 (HECW2), ubiquitin specific peptidase 24 (USP24), ubiquitin family domain containing 1 (UBFD1) and mitochondrial ubiquitin ligase activator of NFKB 1-like (MUL1), Amyloid beta precursor protein (APP) and Heat shock $70 \mathrm{kDa}$ protein 2 (HSPA2) are either the major components or associated with the UPS system $[92,93]$. Those genes targeted by several miRNAs including miR-28, miR-363, miR-2020, miR-24, miR-1207, miR-345 and miR-58 may be the cause of fluctuation of the UPS degradation for ubiquitin proteasome-dependent molecules [94] such as transcriptional coactivator PGC- $1 \alpha$ which acts as a master regulator for mitochondrial biogenesis, to control mitochondrial gene expression indirectly. On the other side, miR-210 and miR-885 targeted genes of ATP synthase mitochondrial F0 complex subunit E (ATP5I), Pyruvate dehydrogenase alpha 1 (PDHA1) and Ubiquinol-cytochrome c reductase complex chaperone (UQCC) [95] could affect cellular ATP generation, followed by influencing the ATP-dependent UPS system [96]. However, further detail information of the interaction between mitochondria and UPS still remains elusive.

\section{Conclusion}

In this study, we modelled the miRNA-mRNA regulatory networks related to muscle fiber type, metabolic enzyme activity and ATP production using the correlation information between expressed miRNAs and target mRNAs as well as muscular phenotypic measurements of Duroc and PiNN pigs. These complex networks may contribute to the muscle phenotypic variations by finetuning the expression of genes. Altogether, the results provide an insight into a regulatory role of miRNAs in muscular energy metabolisms. 


\section{Additional files}

Additional file 1: Definition and measurement of phenotypical traits. (XLSX $11 \mathrm{~kb}$ )

Additional file 2: The primer sequences in qRT-PCR. (XLSX $10 \mathrm{~kb}$ )

Additional file 3: Differentially expressed miRNAs in porcine LD muscle between Duroc and Pietrain breed types at adult stage. (XLSX $17 \mathrm{~kb}$ )

Additional file 4: Different expressed miRNA-mRNA pairs between

Duroc and PiNN after target prediction. (XLSX $130 \mathrm{~kb}$ )

Additional file 5: Individual miRNAs and their correlated phenotypes for Duroc and PiNN. (XLSX 20 kb)

Additional file 6: Individual mRNAs and their correlated phenotypes for Duroc and PiNN. (XLSX 18 kb)

Additional file 7: Phenotype correlated miRNA-mRNA pairs after target prediction for Duroc and PiNN. (XLSX $48 \mathrm{~kb}$ )

\section{Abbreviations}

miRNA, microRNA; STO, slow-twitch-oxidative; FTO, fast-twitch-oxidative; FTG, fast-twitch-glycolytic; PiNN: pietrain; UPS, ubiquitin proteasome system.

\section{Acknowledgements}

The authors thank Annette Jugert and Joana Bittner for excellent technical help.

\section{Funding}

Measurements of mitochondrial respiratory activity and metabolic enzyme activity were supported by the German Research Foundation (WE 4079/1-1) (Deutsche Forschungsgemeinschaft, DFG) in a project initiated and led by Prof. Dr. Michael Wicke (Department of Animal Science, Quality of Food of Animal Origin, Georg-August-University Goettingen) who has left us forever. The publication of this article was funded by the open access funds of the Leibniz Association and the Leibniz Institute for Farm Animal Biology (FBN).

\section{Availability of data and material}

The availability of expression data are in the Gene Expression Omnibus public repository with the GEO accession number GSE80198: GSM2120718GSM2120737.

\section{Authors' contributions}

$\mathrm{XL}$ analysed the microarray data and drafted the manuscript; $\mathrm{FH}$ helped in target prediction analysis. NT, EM, and KW helped in sampling and data collection and drafting the manuscript; SP discussed and contributed to data interpretation and helped in drafting the manuscript. All authors have read and approved the final manuscript.

\section{Competing interests}

The authors declare that they have no competing interests.

\section{Consent for publication}

Not applicable.

\section{Ethics approval and consent to participate}

All experimental procedures, including animal care and tissue sample collection, followed guidelines for safeguarding and good scientific practice in accordance with the German Law of Animal Protection, officially authorized by the Animal Care Committee and authorities [Niedersächsischen Landesamt für Verbraucherschutz und Lebensmittelsicherheit (LAVES) 33.42502/01-47.05].

Received: 29 April 2016 Accepted: 20 June 2016

Published online: 02 August 2016

\section{References}

1. Shukla GC, Singh J, Barik S. MicroRNAs: processing, maturation, target recognition and regulatory functions. Mol Cell Pharmacol. 2011;3:83-92.

2. Gueguen N, Lefaucheur L, Fillaut M, Vincent A, Herpin P. Control of skeletal muscle mitochondria respiration by adenine nucleotides: differential effect of ADP and ATP according to muscle contractile type in pigs. Comp Biochem Physiol B Biochem Mol Biol. 2005;140:287-97.
3. Picard M, Hepple RT, Burelle Y. Mitochondrial functional specialization in glycolytic and oxidative muscle fibers: tailoring the organelle for optima function. Am J Physiol Cell Physiol. 2012;302:C629-41.

4. Schwerzmann K, Hoppeler H, Kayar SR, Weibel ER. Oxidative capacity of muscle and mitochondria: correlation of physiological, biochemical, and morphometric characteristics. Proc Natl Acad Sci U S A. 1989;86:1583-7.

5. Ponsuksili S, Du Y, Hadlich F, Siengdee P, Murani E, Schwerin M, Wimmers K. Correlated mRNAs and miRNAs from co-expression and regulatory networks affect porcine muscle and finally meat properties. BMC Genomics. 2013;14:533.

6. Lee JS, Kim JM, Lim KS, Hong JS, Hong KC, Lee YS. Effects of polymorphisms in the porcine microRNA MIR206 / MIR133B cluster on muscle fiber and meat quality traits. Anim Genet. 2013:44:101-6.

7. Kim JM, Lim KS, Hong JS, Kang JH, Lee YS, Hong KC. A polymorphism in the porcine miR-208b is associated with microRNA biogenesis and expressions of SOX-6 and MYH7 with effects on muscle fibre characteristics and meat quality. Anim Genet. 2015:46:73-7.

8. Hou X, Tang Z, Liu H, Wang N, Ju H, Li K. Discovery of MicroRNAs associated with myogenesis by deep sequencing of serial developmental skeletal muscles in pigs. PLoS One. 2012;7, e52123.

9. Huang TH, Zhu MJ, Li XY, Zhao SH. Discovery of porcine microRNAs and profiling from skeletal muscle tissues during development. PLoS One. 2008; 3, e3225.

10. McDaneld TG, Smith TP, Doumit ME, Miles JR, Coutinho LL, Sonstegard TS, Matukumalli LK, Nonneman DJ, Wiedmann RT. MicroRNA transcriptome profiles during swine skeletal muscle development. BMC Genomics. 2009;10:

11. Li HY, Xi QY, Xiong YY, Liu XL, Cheng X, Shu G, Wang SB, Wang LN, Gao P, Zhu XT, et al. Identification and comparison of microRNAs from skeletal muscle and adipose tissues from two porcine breeds. Anim Genet. 2012;43: 704-13.

12. Hocquette JF, Ortigues-Marty I, Vermorel M. Manipulation of tissue energy metabolism in meat-producing ruminants - review. Asian Australas J Anim Sci. 2001;14:720-32.

13. Aschrafi A, Kar AN, Natera-Naranjo O, MacGibeny MA, Gioio AE, Kaplan BB. MicroRNA-338 regulates the axonal expression of multiple nuclear-encoded mitochondrial mRNAs encoding subunits of the oxidative phosphorylation machinery. Cell Mol Life Sci. 2012;69:4017-27.

14. Chen Z, Li Y, Zhang H, Huang P, Luthra R. Hypoxia-regulated microRNA-210 modulates mitochondrial function and decreases ISCU and COX10 expression. Oncogene. 2010;29:4362-8.

15. Nishi H, Ono K, Iwanaga Y, Horie T, Nagao K, Takemura G, Kinoshita M Kuwabara Y, Mori RT, Hasegawa K, et al. MicroRNA-15b modulates cellular ATP levels and degenerates mitochondria via Arl2 in neonatal rat cardiac myocytes. J Biol Chem. 2010;285:4920-30.

16. Siengdee $\mathrm{P}$, Trakooljul N, Murani E, Schwerin M, Wimmers K, Ponsuksili S. MicroRNAs regulate cellular ATP levels by targeting mitochondrial energy metabolism genes during C2C12 myoblast differentiation. PLoS One. 2015; 10, e0127850

17. Aoi W, Naito Y, Mizushima K, Takanami Y, Kawai Y, Ichikawa H, Yoshikawa T. The microRNA miR-696 regulates PGC-1\{alpha\} in mouse skeletal muscle in response to physical activity. Am J Physiol Endocrinol Metab. 2010;298: E799-806

18. Liu X, Du Y, Trakooljul N, Brand B, Murani E, Krischek C, Wicke M, Schwerin M, Wimmers K, Ponsuksili S. Muscle transcriptional profile based on muscle fiber, mitochondrial respiratory activity, and metabolic enzymes. Int J Biol Sci. 2015;11:1348-62.

19. Werner C, Natter R, Schellander K, Wicke M. Mitochondrial respiratory activity in porcine longissimus muscle fibers of different pig genetics in relation to their meat quality. Meat Sci. 2010;85:127-33.

20. Werner C, Natter R, Wicke M. Changes of the activities of glycolytic and oxidative enzymes before and after slaughter in the longissimus muscle of Pietrain and Duroc pigs and a Duroc-Pietrain crossbreed. J Anim Sci. 2010;88:4016-25.

21. Krischek C, Natter R, Wigger R, Wicke M. Adenine nucleotide concentrations and glycolytic enzyme activities in longissimus muscle samples of different pig genotypes collected before and after slaughter. Meat Sci. 2011:89:217-20.

22. Benjamini $Y$, Hochberg Y. Controlling the false discovery rate: a practical and powerful approach to multiple testing. J R Stat Soc Ser B Methodol. 1995;57:289-300.

23. Rehmsmeier M, Steffen P, Hochsmann M, Giegerich R. Fast and effective prediction of microRNA/target duplexes. RNA. 2004;10:1507-17. 
24. Kruger J, Rehmsmeier M. RNAhybrid: microRNA target prediction easy, fast and flexible. Nucleic Acids Res. 2006;34:W451-4.

25. Lewis BP, Burge CB, Bartel DP. Conserved seed pairing, often flanked by adenosines, indicates that thousands of human genes are microRNA targets. Cell. 2005;120:15-20.

26. Hafner M, Landthaler M, Burger L, Khorshid M, Hausser J, Berninger P, Rothballer A, Ascano Jr M, Jungkamp AC, Munschauer M, et al. Transcriptome-wide identification of RNA-binding protein and microRNA target sites by PAR-CLIP. Cell. 2010;141:129-41.

27. Chi SW, Zang JB, Mele A, Darnell RB. Argonaute HITS-CLIP decodes microRNA-mRNA interaction maps. Nature. 2009;460:479-86.

28. Hausser J, Syed AP, Bilen B, Zavolan M. Analysis of CDS-located miRNA target sites suggests that they can effectively inhibit translation. Genome Res. 2013;23:604-15.

29. Lytle JR, Yario TA, Steitz JA. Target mRNAs are repressed as efficiently by microRNA-binding sites in the 5' UTR as in the 3' UTR. Proc Natl Acad Sci U S A. 2007;104:9667-72.

30. Xu W, San Lucas A, Wang Z, Liu Y. Identifying microRNA targets in different gene regions. BMC Bioinformatics. 2014;15 Suppl 7:\$4.

31. Cline MS, Smoot M, Cerami E, Kuchinsky A, Landys N, Workman C, Christmas R, Avila-Campilo I, Creech M, Gross B, et al. Integration of biological networks and gene expression data using Cytoscape. Nat Protoc. 2007;2:2366-82.

32. Huber K, Petzold J, Rehfeldt C, Ender K, Fiedler I. Muscle energy metabolism: structural and functional features in different types of porcine striated muscles. J Muscle Res Cell Motil. 2007;28:249-58.

33. Essen-Gustavsson B, Karlsson A, Lundstrom K, Enfalt AC. Intramuscular fat and muscle fibre lipid contents in halothane-gene-free pigs fed high or low protein diets and its relation to meat quality. Meat Sci. 1994;38:269-77.

34. Karlsson AH, Klont RE, Fernandez X. Skeletal muscle fibres as factors for pork quality. Livest Prod Sci. 1999:60:255-69.

35. Karlsson A, Essen-Gustavsson B, Lundstrom K. Muscle glycogen depletion pattern in halothane-gene-free pigs at slaughter and its relation to meat quality. Meat Sci. 1994;38:91-101.

36. Hou X, Yang Y, Zhu S, Hua C, Zhou R, Mu Y, Tang Z, Li K. Comparison of skeletal muscle miRNA and mRNA profiles among three pig breeds. Mol Genet Genomics. 2016;291:559-73.

37. Tang Z, Yang Y, Wang Z, Zhao S, Mu Y, Li K. Integrated analysis of miRNA and mRNA paired expression profiling of prenatal skeletal muscle development in three genotype pigs. Sci Rep. 2015;5:15544

38. Jing L, Hou Y, Wu H, Miao Y, Li X, Cao J, Brameld JM, Parr T, Zhao S. Transcriptome analysis of mRNA and miRNA in skeletal muscle indicates an important network for differential Residual Feed Intake in pigs. Sci Rep. 2015;5:11953.

39. Lecker SH, Solomon V, Mitch WE, Goldberg AL. Muscle protein breakdown and the critical role of the ubiquitin-proteasome pathway in normal and disease states. J Nutr. 1999;129:227S-37S.

40. Murton AJ, Constantin D, Greenhaff PL. The involvement of the ubiquitin proteasome system in human skeletal muscle remodelling and atrophy. Biochim Biophys Acta. 2008;1782:730-43.

41. Huynh TP, Murani E, Maak S, Ponsuksili S, Wimmers K. UBE3B and ZRANB1 polymorphisms and transcript abundance are associated with water holding capacity of porcine M. longissimus dorsi. Meat Sci. 2013;95:166-72.

42. Loan HT, Murani E, Maak S, Ponsuksili S, Wimmers K. UBXN1 polymorphism and its expression in porcine M. longissimus dorsi are associated with water holding capacity. Mol Biol Rep. 2014:41:1411-8.

43. Patron JP, Fendler A, Bild M, Jung U, Muller H, Arntzen MO, Piso C, Stephan C, Thiede B, Mollenkopf HJ, et al. MiR-133b targets antiapoptotic genes and enhances death receptor-induced apoptosis. PLoS One. 2012;7, e35345.

44. Robinson PM, Chuang TD, Sriram S, Pi L, Luo XP, Petersen BE, Schultz GS. MicroRNA signature in wound healing following excimer laser ablation: role of miR-133b on TGFbeta1, CTGF, SMA, and COL1A1 expression levels in rabbit corneal fibroblasts. Invest Ophthalmol Vis Sci. 2013;54:6944-51.

45. Cicek IO, Karaca S, Brankatschk M, Eaton S, Urlaub H, Shcherbata HR. Hedgehog signaling strength is orchestrated by the mir-310 cluster of microRNAs in response to diet. Genetics. 2016;202:1167-83.

46. Chen L, Cui J, Hou J, Long J, Li C, Liu L. A novel negative regulator of adipogenesis: microRNA-363. Stem Cells. 2014;32:510-20.

47. Sarparanta J, Blandin G, Charton K, Vihola A, Marchand S, Milic A, Hackman P, Ehler E, Richard I, Udd B. Interactions with M-band titin and calpain 3 link myospryn (CMYA5) to tibial and limb-girdle muscular dystrophies. J Biol Chem. 2010;285:30304-15.
48. Xu X, Xu X, Yin Q, Sun L, Liu B, Wang Y. The molecular characterization and associations of porcine cardiomyopathy asssociated 5 (CMYA5) gene with carcass trait and meat quality. Mol Biol Rep. 2011;38:2085-90.

49. Altuwaijri S, Lee DK, Chuang KH, Ting HJ, Yang Z, Xu Q, Tsai MY, Yeh S, Hanchett $\mathrm{LA}$, Chang HC, et al. Androgen receptor regulates expression of skeletal musclespecific proteins and muscle cell types. Endocrine. 2004;25:27-32.

50. Lim D, Lee SH, Kim NK, Cho YM, Chai HH, Seong HH, Kim H. Gene coexpression analysis to characterize genes related to marbling trait in Hanwoo (Korean) cattle. Asian-Australas J Anim Sci. 2013;26:19-29.

51. Schleinitz D, Kloting N, Bottcher Y, Wolf S, Dietrich K, Tonjes A, Breitfeld J, Enigk B, Halbritter J, Korner A, et al. Genetic and evolutionary analyses of the human bone morphogenetic protein receptor 2 (BMPR2) in the pathophysiology of obesity. PLoS One. 2011;6, e16155.

52. Goodman CA, McNally RM, Hoffmann FM, Hornberger TA. Smad3 induces atrogin-1, inhibits mTOR and protein synthesis, and promotes muscle atrophy in vivo. Mol Endocrinol. 2013;27:1946-57.

53. Tiano JP, Springer DA, Rane SG. SMAD3 negatively regulates serum irisin and skeletal muscle FNDC5 and peroxisome proliferator-activated receptor gamma coactivator 1-alpha (PGC-1alpha) during exercise. J Biol Chem. 2015;290:7671-84.

54. Lin J, Wu H, Tarr PT, Zhang CY, Wu Z, Boss O, Michael LF, Puigserver P, Isotani E, Olson EN, et al. Transcriptional co-activator PGC-1 alpha drives the formation of slow-twitch muscle fibres. Nature. 2002;418:797-801.

55. LeBleu VS, O'Connell JT, Gonzalez Herrera KN, Wikman H, Pantel K, Haigis MC, de Carvalho FM, Damascena A, Domingos Chinen LT, Rocha RM, et al. PGC-1alpha mediates mitochondrial biogenesis and oxidative phosphorylation in cancer cells to promote metastasis. Nat Cell Biol. 2014;16:992-1003. 1001-1015.

56. Ros S, Schulze A. Balancing glycolytic flux: the role of 6-phosphofructo-2kinase/fructose 2,6-bisphosphatases in cancer metabolism. Cancer Metab. 2013;1:8.

57. Williams AH, Liu N, van Rooij E, Olson EN. MicroRNA control of muscle development and disease. Curr Opin Cell Biol. 2009;21:461-9.

58. Liu J, Liang X, Gan Z. Transcriptional regulatory circuits controlling muscle fiber type switching. Sci China Life Sci. 2015;58:321-7.

59. van Rooij E, Quiat D, Johnson BA, Sutherland LB, Qi X, Richardson JA, Kelm Jr RJ, Olson EN. A family of microRNAs encoded by myosin genes governs myosin expression and muscle performance. Dev Cell. 2009;17:662-73.

60. von Hofsten J, Elworthy S, Gilchrist MJ, Smith JC, Wardle FC, Ingham PW. Prdm1- and Sox6-mediated transcriptional repression specifies muscle fibre type in the zebrafish embryo. EMBO Rep. 2008;9:683-9.

61. Ljubicic V, Burt M, Lunde JA, Jasmin BJ. Resveratrol induces expression of the slow, oxidative phenotype in $\mathrm{mdx}$ mouse muscle together with enhanced activity of the SIRT1-PGC-1alpha axis. Am J Physiol Cell Physiol. 2014:307:C66-82.

62. Wu J, Zheng C, Wang X, Yun S, Zhao Y, Liu L, Lu Y, Ye Y, Zhu X, Zhang C, et al. MicroRNA-30 family members regulate calcium/calcineurin signaling in podocytes. J Clin Invest. 2015;125:4091-106.

63. Wang $X$, Wang $K$, Han L, Zhang A, Shi Z, Zhang K, Zhang H, Yang S, Pu P, Shen $C$, et al. PRDM1 is directly targeted by miR-30a-5p and modulates the Wnt/beta-catenin pathway in a Dkk1-dependent manner during glioma growth. Cancer Lett. 2013;331:211-9.

64. Ning X, Liu S, Qiu Y, Li G, Li Y, Li M, Yang G. Expression profiles and biological roles of miR-196a in swine. Genes (Basel). 2016;7:5.

65. Kureel J, Dixit M, Tyagi AM, Mansoori MN, Srivastava K, Raghuvanshi A, Maurya R, Trivedi R, Goel A, Singh D. miR-542-3p suppresses osteoblast cell proliferation and differentiation, targets BMP-7 signaling and inhibits bone formation. Cell Death Dis. 2014;5:e1050.

66. Zheng L, Liu JM, Wang JX, Li MZ, Lian WG, Xie P, Liu SF. Effect of bone morphogenetic protein 7 on differentiation of adipose derived mesenchymal stem cells into brown adipocytes in rats. Zhongguo Yi Xue Ke Xue Yuan Xue Bao. 2014;36:654-9.

67. Townsend KL, An D, Lynes MD, Huang TL, Zhang H, Goodyear LJ, Tseng YH. Increased mitochondrial activity in BMP7-treated brown adipocytes, due to increased CPT1- and CD36-mediated fatty acid uptake. Antioxid Redox Signal. 2013;19:243-57

68. Wang L, Yuan Y, Li J, Ren H, Cai Q, Chen X, Liang H, Shan H, Fu ZD, Gao X, et al. MicroRNA-1 aggravates cardiac oxidative stress by post-transcriptional modification of the antioxidant network. Cell Stress Chaperones. 2015;20:411-20.

69. Hong JS, Noh SH, Lee JS, Kim JM, Hong KC, Lee YS. Effects of polymorphisms in the porcine microRNA miR-1 locus on muscle fiber type composition and miR-1 expression. Gene. 2012;506:211-6. 
70. Wang B, Sun F, Dong N, Sun Z, Diao Y, Zheng C, Sun J, Yang Y, Jiang D. MicroRNA-7 directly targets insulin-like growth factor 1 receptor to inhibit cellular growth and glucose metabolism in gliomas. Diagn Pathol. 2014;9:211.

71. Yu Y, Chai J, Zhang H, Chu W, Liu L, Ma L, Duan H, Li B, Li D. miR-194 promotes burn-induced hyperglycemia via attenuating IGF-IR expression. Shock. 2014:42:578-84.

72. Setyowati Karolina D, Sepramaniam S, Tan HZ, Armugam A, Jeyaseelan K. miR-25 and miR-92a regulate insulin I biosynthesis in rats. RNA Biol. 2013;10:1365-78.

73. Rajpathak SN, Gunter MJ, Wylie-Rosett J, Ho GY, Kaplan RC, Muzumdar R, Rohan TE, Strickler HD. The role of insulin-like growth factor-I and its binding proteins in glucose homeostasis and type 2 diabetes. Diabetes Metab Res Rev. 2009;25:3-12.

74. Clemmons DR. Role of insulin-like growth factor iin maintaining normal glucose homeostasis. Horm Res. 2004;62 Suppl 1:77-82.

75. Pan L, Huang BJ, Ma XE, Wang SY, Feng J, LV F, Liu Y, Liu Y, Li CM, Liang DD, et al. MiR-25 protects cardiomyocytes against oxidative damage by targeting the mitochondrial calcium uniporter. Int J Mol Sci. 2015;16:5420-33.

76. Wahlquist C, Jeong D, Rojas-Munoz A, Kho C, Lee A, Mitsuyama S, van Mil A, Park WJ, Sluijter JP, Doevendans PA, et al. Inhibition of miR-25 improves cardiac contractility in the failing heart. Nature. 2014;508:531-5.

77. Cheng Z, Tseng Y, White MF. Insulin signaling meets mitochondria in metabolism. Trends Endocrinol Metab. 2010;21:589-98.

78. Stump CS, Short KR, Bigelow ML, Schimke JM, Nair KS. Effect of insulin on human skeletal muscle mitochondrial ATP production, protein synthesis, and mRNA transcripts. Proc Natl Acad Sci U S A. 2003;100:7996-8001.

79. Sultan KR, Dittrich BT, Leisner E, Paul N, Pette D. Fiber type-specific expression of major proteolytic systems in fast- to slow-transforming rabbit muscle. Am J Physiol Cell Physiol. 2001;280:C239-47.

80. Hernandez-Torres F, Aranega AE, Franco D. Identification of regulatory elements directing miR-23a-miR-27a-miR-24-2 transcriptional regulation in response to muscle hypertrophic stimuli. Biochim Biophys Acta. 2014;1839:885-97.

81. Allen DL, Loh AS. Posttranscriptional mechanisms involving microRNA-27a and b contribute to fast-specific and glucocorticoid-mediated myostatin expression in skeletal muscle. Am J Physiol Cell Physiol. 2011;300:C124-37.

82. Annalora AJ, Goodin DB, Hong WX, Zhang Q, Johnson EF, Stout CD. Crystal structure of CYP24A1, a mitochondrial cytochrome P450 involved in vitamin D metabolism. J Mol Biol. 2010;396:441-51.

83. Ricciardi CJ, Bae J, Esposito D, Komarnytsky S, Hu P, Chen J, Zhao L. 1,25Dihydroxyvitamin D3/vitamin D receptor suppresses brown adipocyte differentiation and mitochondrial respiration. Eur J Nutr. 2015:54:1001-12.

84. Pickova A, Potocky M, Houstek J. Assembly factors of F1FO-ATP synthase across genomes. Proteins. 2005;59:393-402.

85. Yang Z, Lanks CW, Tong L. Molecular mechanism for the regulation of human mitochondrial NAD(P) +-dependent malic enzyme by ATP and fumarate. Structure. 2002:10:951-60.

86. Xu X, Shi YC, Gao W, Mao G, Zhao G, Agrawal S, Chisolm GM, Sui D, Cui MZ The novel presenilin-1-associated protein is a proapoptotic mitochondrial protein. J Biol Chem. 2002;277:48913-22.

87. Lamarca V, Sanz-Clemente A, Perez-Pe R, Martinez-Lorenzo MJ, Halaihel N, Muniesa P, Carrodeguas JA. Two isoforms of PSAP/MTCH1 share two proapoptotic domains and multiple internal signals for import into the mitochondrial outer membrane. Am J Physiol Cell Physiol. 2007;293:C1347-61.

88. Kerner J, Hoppel C. Fatty acid import into mitochondria. Biochimica et Biophysica Acta (BBA) - Molecular and Cell Biology of Lipids. 2000;1486:1-17.

89. Branco DM, Arduino DM, Esteves AR, Silva DF, Cardoso SM, Oliveira CR. Cross-talk between mitochondria and proteasome in Parkinson's disease pathogenesis. Front Aging Neurosci. 2010;2:17

90. Ross JM, Olson L, Coppotelli G. Mitochondrial and ubiquitin proteasome system dysfunction in ageing and disease: two sides of the same coin? Int J Mol Sci. 2015;16:19458-76.

91. Duke DC, Moran LB, Kalaitzakis ME, Deprez M, Dexter DT, Pearce RK, Graeber MB. Transcriptome analysis reveals link between proteasomal and mitochondrial pathways in Parkinson's disease. Neurogenetics. 2006;7:139-48.

92. Hong $\mathrm{L}$, Huang $\mathrm{HC}$, Jiang ZF. Relationship between amyloid-beta and the ubiquitin-proteasome system in Alzheimer's disease. Neurol Res. 2014;36:276-82.

93. Shiber A, Ravid T. Chaperoning proteins for destruction: diverse roles of Hsp70 chaperones and their co-chaperones in targeting misfolded proteins to the proteasome. Biomolecules. 2014;4:704-24.

94. Trausch-Azar J, Leone TC, Kelly DP, Schwartz AL. Ubiquitin proteasomedependent degradation of the transcriptional coactivator PGC-1\{alpha\} via the N-terminal pathway. J Biol Chem. 2010;285:40192-200.
95. Tucker EJ, Wanschers BF, Szklarczyk R, Mountford HS, Wijeyeratne XW, van den Brand MA, Leenders AM, Rodenburg RJ, Reljic B, Compton AG, et al. Mutations in the UQCC1-interacting protein, UQCC2, cause human complex III deficiency associated with perturbed cytochrome $b$ protein expression. PLoS Genet. 2013;9, e1004034

96. Huang H, Zhang X, Li S, Liu N, Lian W, McDowell E, Zhou P, Zhao C, Guo H,

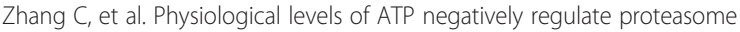
function. Cell Res. 2010;20:1372-85

\section{Submit your next manuscript to BioMed Central and we will help you at every step:}

- We accept pre-submission inquiries

- Our selector tool helps you to find the most relevant journal

- We provide round the clock customer support

- Convenient online submission

- Thorough peer review

- Inclusion in PubMed and all major indexing services

- Maximum visibility for your research

Submit your manuscript at www.biomedcentral.com/submit
) Biomed Central 